Arqueología y Sociedad,

$N^{\circ} 17,2006$

\title{
La arqueología marxista en el Perú: Génesis, despliegue y futuro
}

\section{Henry Tantaleán*}

\begin{abstract}
Resumen
El presente artículo describe el desarrollo histórico de una línea teórica en el Perú que denominamos arqueología marxista. Dicha arqueología está fundamentada en los escritos de Marx y Engels, aunque como veremos, muchos intelectuales no los leyeron necesariamente desde la ontología y la epistemología materialista dialéctica. Asimismo, se pretende situar a la arqueología marxista dentro de su contexto de producción para entender mejor sus planos sociológico e ideológico. Lo que podemos percibir en nuestro análisis historiográfico, es que cada vez que se quiere describir alguno de los tres momentos del desarrollo de la arqueología marxista aquí planteados, un autor monopolizará la escena arqueológica. En ei primer y tercer momento, dicha situación se debe a que fueron arqueólogos orgánicos de los gobiernos peruanos los que asumieron tal protagonismo. En el segundo momento, la inexistencia de una plataforma política oficial opuesta o no concordante con el marxismo, supuso que fuese un autor desligado de los círculos académicos oficiales (dominantes) el que sobresaliese de manera marginal aunque vital para la continuidad de esta forma de hacer arqueología en el Perú del siglo XX.
\end{abstract}

Palabras claves: Arqueología, marxismo, ideología, indigenismo, nacionalismo, teoría, praxis.

\begin{abstract}
This paper describes the historical development of a theoretical trend in Peru that we will call Marxist Archaeology. This archaeology is based in the classical writings of Marx and Engels, althought like we will see many of the authors made different readings of these authors, not necesarilly rooted on the onthology and epysthemology of Dialectical Mmaterialism. In order to get our aim, we locate this kind of archaeology inside of its production context as a means to understand in a better way its sociological and ideological perspectives. We will perceive throught our historygraphical analysis that every time that we try to describe any of the studied moments of this marxist archaeology, we willfind one author monopolizing the archaeological scene. We believe that in the case of the first and third moments, this situation was possible because the authors mentioned were organically attached to the peruvian governments. In the second moment, the inexistence of an official political platform concordant or tolerant with the marxism, supossed that an author unrrelated with the official (dominant) academic circles will protagonize, althought in a marginal way, this trend, becoming a necessary figure for the continuity of this way of doing archaeology in the Peru of the twentieth century.
\end{abstract}

Keywords: Archaeology, Marxism, ideology, indigenism, nacionalism, theory, praxis.

\footnotetext{
* Universidad Autónoma de Barcelona / Universidad Nacional Mayor de San Marcos. Correo electrónico: henrytantalean@yahoo.es
} 


\section{"Somos lo que hacemos para cambiar lo que somos"}

(Frase escrita en una pared. Barrio de Gracia, Barcelona, 2005)

\section{Introducción}

La arqueología como disciplina científica no nació en los países latinoamericanos hasta las últimas décadas del siglo XIX (Politis 1995: 198 199) y, en el caso concreto del Perú, en los albores del siglo XX (Lumbreras 1991, Pozzi-Escott 2002). Paradójicamente, dicha arqueología se inició con la presencia en estos países de investigadores extranjeros, como el alemán Max Uhle para el caso peruano (Politis 1995: 200). A través de ellos, la teoría dominante de ese entonces, el evolucionismo cultural ${ }^{\mathrm{I}}$, fue instaurada para la interpretación de las sociedades prehispánicas.

En el siglo XX, la influencia de los Estados Unidos en Latinoamérica se hizo notar conforme sus intereses económicos y políticos iban aumentando (Cotler 2005, Patterson 1986). De esta forma, el evolucionismo social con el cual se inició la arqueología pretendió ser sustituido por el historicismo cultural, una teoría que en ese marco de colonialismo económico e ideológico, servía de mejor manera para los propósitos imperialistas.

Sin embargo, en los años previos a que el historicismo cultural adquiriese relevancia en EE.UU., en países como Perú y México se desarrolló un movimiento social y político contrario al colonialismo económico e ideológico denominado "indigenismo". Este movimiento idealizaba el pasado prehispánico, principalmente al Imperio Incaico, y fue llevado al discurso arqueológico por Luis $\mathrm{E}$. Valcárcel a comienzos de siglo XX (ver Patterson 1994: 531). Este indigenismo fue utilizado por la clase dirigente, representada en el presidente Augusto B. Leguía (1919-1930), para crear un nacionalismo que afiance al Estado a través de la idealización del pasado prehispánico. Con ese mismo objetivo, Julio C. Tello se convertiría en el "arqueólogo oficial" de esta políti$\mathrm{ca}$.

Así, la arqueología marxista en el Perú surgiría de la contradicción entre la ideología de grupos económico-sociales nacionalistasanticolonialistas y una ideología de clase claramente relacionada al capital internacional norteamericano. En ambos casos, dichas ideologías fueron producidas y reproducidas por grupos de la burguesía intelectual nacional. Con ese sustrato ideológico, que tuvo como fundamento las contradicciones económicas y sociales, no transcurrió mucho tiempo antes de que se adoptarán perspectivas materialistas históricas en algunos de los gobiernos que así lo posibilitaron.

\section{Primer momento de la arqueología marxista: indigenismo y arqueología}

Esta arqueología se podría describir como parte del movimiento indigenista, cuyos autores estuvieron influenciados por las ideas políticas de izquierda. En principio, los objetivos originales del movimiento indigenista se encaminaban hacia la superación de la miserable condición social y económica en que se encontraba el "indio", principalmente por su explotación en el Perú de fines del siglo XIX y comienzos del XX. De este modo, por ejemplo, en el prólogo de

\footnotetext{
' Si bien hasta los clásicos marxistas reprodujeron en parte el evolucionismo social de su momento histórico, en la actualidad se ha superado la ortodoxia en la que se vieron sujetos sus primeros seguidores. En ese sentido, la dialéctica debe trascender a las explicaciones históricas.
} 
Tempestad en los Andes de Valcárcel (1927), José Carlos Mariátegui escribía: "La miseria moral y material de la raza indígena aparece (...) como una simple consecuencia del régimen económico y social que sobre ella pesa desde hace siglos. Ese régimen sucesor de la feudalidad colonial, es el "gamonalismo". Bajo su imperio, no se puede hablar seriamente de redención del indio".

Paradójicamente, este primer indigenismo se anclaba en un pasado prehispánico idealizado. Desde la política se tenía la certeza que el Imperio Incaico, había sido "comunista agrario" o "socialista" (Mariátegui 1994 [1928]). Desde esta posición ideológica se aspiraba a un regreso al pasado prehispánico, cuestión posible porque los indígenas del siglo XX conservaban "elementos" o "esencias" de dicho comunismo o socialismo andino (Liss 1984: 135-136). Dichas posiciones tuvieron su correlato en los partidos políticos de izquierda gestados en esa época: el Partido Socialista (denominado como Partido Comunista del Perú en 1929, tras la muerte de su fundador Mariátegui) y el APRA (fundado en 1924 por Víctor Raúl Haya de la Torre), y que eran contrarios a los grupos que detentaban el poder político bajo el gobierno de Leguía. El indigenismo encajó en los programas políticos de ambos partidos puesto que la contradicción a superar era la existente entre la clase explotada (masa indígena y proletaria) y la clase explotadora (representada en ese entonces por los latifundistas y la oligarquía). Sin embargo, ambos partidos anti-oficialistas aspiraban también a la formación de una "nación peruana"'. Hay que agre. gar que el indigenismo original, también fue consecuencia de una posición política antiimperialista en contra de los Estados Unidos, cuestión que, como veremos más abajo, cambiaría radicalmente.
La oligarquía no tardaría en reaccionar ante ese primer indigenismo, el cual despertaba preocupación por el ataque constante a sus intereses económico-políticos. Por ello, intentó manipularlo. Este accionar se vio representado, por ejemplo, en el libro El Imperio Socialista de los Incas (Baudin [1928]1955) en el cual se reconocía un gobierno (Estado) incaico paternalista, pero analizado bajo el racismo imperante de la época. Esta visión racista justificaba la incompetencia e inferioridad de la "raza indígena" debido a sus deficiencias físicas y mentales que le impedían la emancipación (Baudin 1955 [1928]: 175).

Tras estas primeras manipulaciones, el indigenismo fue adecuado y utilizado hábilmente por el programa político de Leguía, y sus aliados de la clase dominante ${ }^{3}$, para conseguir el objetivo contrario al de sus orígenes. El nuevo objetivo era permitir una mejor expansión de los enclaves económicos norteamericanos en el Perú. De hecho, Leguía llegó al poder con el apoyo de los representantes de los Estados Unidos en Lima y de los fabricantes de armas norteamericanos (Haworth 1992: 175), y su política coincidía con una clara sumisión a los lineamientos de la política hemisférica estadounidense (Pease 1999: 144). Esta situación también fue posible por la incapacidad de la burguesía nacional para producir una identidad nacional con el objeto de defender sus propios intereses económicos. Dicha burguesía se rendiría pronto ante los intereses y presiones imperialistas y reproduciría el discurso oficial (Quijano 1985: 39-40).

De esta manera, se había dado un giro de 180 grados a los objetivos del indigenismo original, siendo ahora utilizado para legitimar la explotación de la población indígena por los terratenientes y clases burguesas. Éstos últimos fueron los encargados de llevar a cabo el plan político de

\footnotetext{
${ }^{2}$ Aunque personalmente, Mariátegui insistió en que la lucha debería ser clasista y que él no era nacionalista sino socialista (Liss 1984: 133).

'Por ejemplo, en consecuencia de esta política de gobierno se fundó el Patronato de la Raza Indígena en 1922 (Pease 1999: 189).
} 
Leguía. Se llegaría al extremo cuando en 1930 Luis M. Sánchez Cerro implanta una política explícitamente pro fascista apoyada por su partido Unión Revolucionaria. En esta época los discursos indigenistas, básicamente desde el aprismo y marxismo, no serían tolerados y se proscribiría a estos partidos por ser opositores al gobierno (Pease 1999: 174-184).

Entre los intelectuales más relevantes de la línea indigenista tenemos a Luis E. Valcárcel (1928), Arze (1941), Louis Baudin (1928), Tudela (1905), Ugarte (1921) e Hildebrando Castro Pozo $(1924,1936)$.

\section{Tempestad en los Andes: Luis E. Valcárcel} (1891-1987)

Luis E. Valcárcel (1891-1987) se inició en el ambiente académico como profesor de historia de la Universidad San Antonio Abad del Cuzco. Ya desde allí se alineaba con el movimiento indigenista, por ejemplo, firmando manifiestos junto a José Carlos Mariátegui, Julio C. Tello, Rebeca Carrión y José Uriel García, todos ellos pertenecientes a dicho movimiento. Publicó un primer libro titulado Tempestad en los Andes (1928), considerado como su verdadero manifiesto indigenista. Como comenta Rodrigo Montoya: "Tempestad en los Andes", fue el panfleto semiliterario y semipolítico de Luis E. Valcárcel, el joven radical indigenista de los años veinte, ardiente y fogoso, que anunciaba la llegada de una revolución india que bajaría desde los Andes y que estaba sólo a la espera del Lenín que la dirigiera" (Montoya 1999).

Así pues, el indigenismo inicial de Valcárcel estaba íntimamente relacionado al marxismo. Sin embargo, dicha postura radical se fue suavizando con el pasar de los años y los nuevos contextos políticos. Producto de ello, Valcárcel ocupó la presidencia del Instituto Cultural Peruano Norteamericano en Lima, cargo que resulta contradictorio a la luz de su discurso inicial. En este segundo periodo de su postura indigenista-nacionalista, favorecida por la coyuntura política, impulsó ideas que se iban desviando cada vez más de su postura inicial. Así, sus esfuerzos tomaron una postura eminentemente oficialista al ser nombrado ministro de estado, cuando creó el Instituto Indigenista Peruano y fue director del Museo de la Cultura Peruana. Por otro lado, Valcárcel auspiciaría la fundación en 1946 del Instituto de Etnología de la Universidad de San Marcos en Lima, germen de la arqueología como carrera universitaria en dicha casa de estudios.

Valcárcel encontraría la referida coyuntura política durante el segundo gobierno o el "oncenio" de Augusto B. Leguía (1919-1930). Por eso, si bien Valcárcel fue el productor oficial de la evidencia material para el indigenismo, no pudo escapar al ambiente político de su época, concentrándose en la reproducción de un sentimiento nacionalista, apropiado y utilizado por el Gobierno al cual se alió. Así, terminó convirtiéndose en el intelectual orgánico de la burguesía

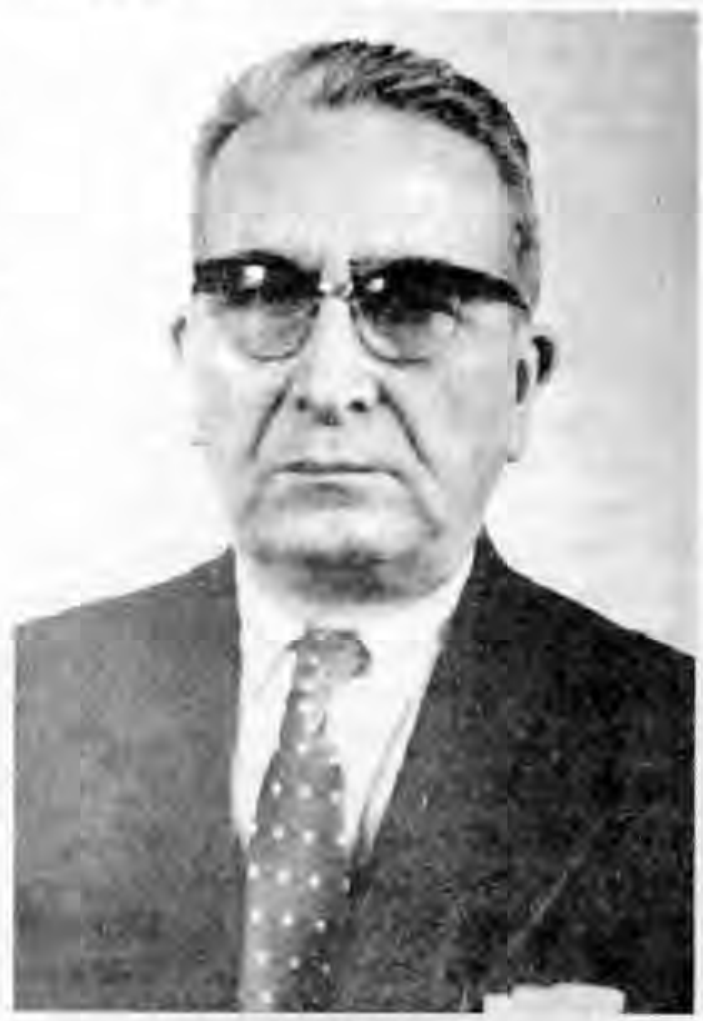

Luis E. Valcárcel. 
andina urbana y rural que irrumpió en el Perú a partir de 1930 (Aguirre-Morales 2001). De esta manera, se trocó en un indigenista-nacionalista.

El ambiente académico también hizo lo suyo en la formación de Valcárcel, revistiéndolo de una perspectiva teórica evolucionista social y una metodología etnográfica y etnohistórica (ver Valcárcel 1925, 1927, 1932a, 1932b, 1935). Valcárcel, también, estuvo influenciado por el difusionismo -semejante al que desarrolló Julio C. Tello, quien también apoyó el proyecto nacionalista de Leguía desde su perspectiva autóctonista e indigenista- lo que condujo en términos socio-políticos a una legitimación de la dominación de la población indígena por la clase burguesa. Finalmente, se dio una lucha entre estos dos intelectuales que la cobertura política se encargo de dirimir.

Segundo momento de la arqueología marxista peruana: Emilio Choy

El siguiente momento de la arqueología marxista peruana se debe a la producción intelectual de Emilio Choy. Para comprender su marginalidad académica (Macera 1979), más allá de que nunca desarrolló una carrera académica típica, podríamos ahondar en lo que hemos denominado como el fenómeno histórico cultu$\mathrm{ral} /$ neoevolucionista.

Éste se dio entre las décadas de 1940 y 1968 , en la que se mantuvo la apertura a los intereses capitalistas norteamericanos. Este periodo se iniciaría con el gobierno de Manuel Prado, quien mantuvo la tradición política pro-oligárquica de forma explícita entre 1939 y 1945 (Haworth 1992: 170). Durante la II Guerra Mundial, Prado provocó una coyuntura favorable para redimir al país con los aliados. Rompió relaciones con el eje fascista y le declaró la guerra a Alemania en $1940^{4}$. Con ese mismo propósito, firmó tratados de préstamos y arriendos con EE.UU. y permitió

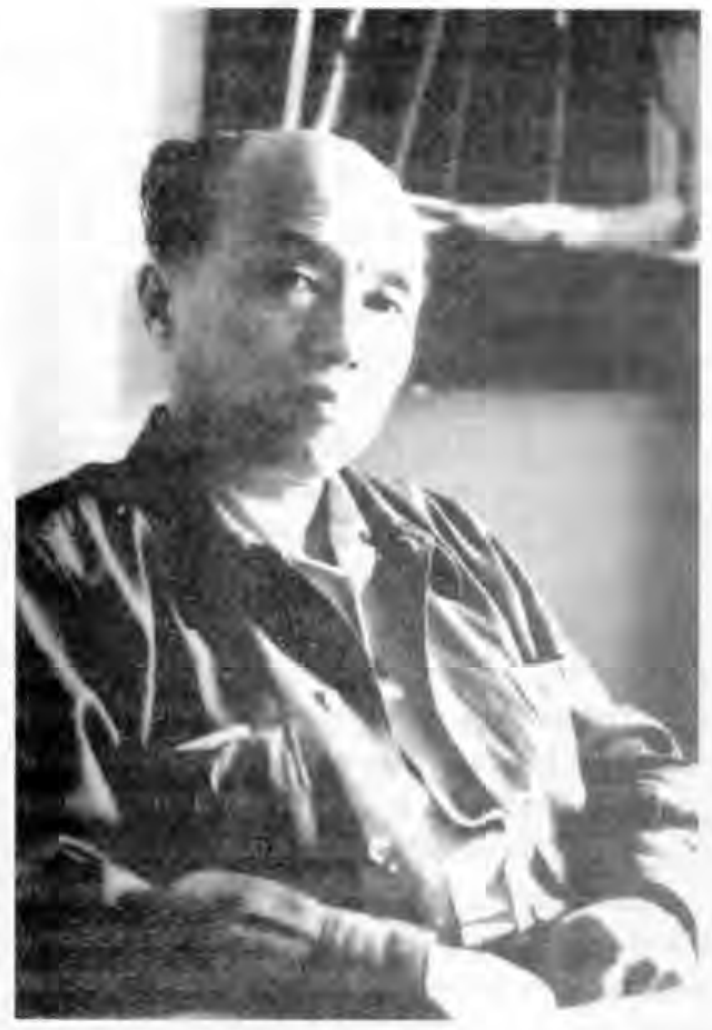

Emilio Choy.

el establecimiento de una base norteamericana en el puerto petrolero de Talara. También, se deportó a miles de residentes japoneses a los que previamente se les había confiscado sus propiedades (Haworth 1992: 176). Asimismo, se aceptó la voluntad norteamericana al establecerse una política de estabilidad de precios de las materias primas nacionales a cambio de la reducción de tarifas arancelarias norteamericanas. Como anota Cotler (1978: 254): "el Perú se convirtió súbitamente en guardián y defensor de las "cuatro libertades" rooseveltianas, esperando así gozar de una retribución correspondiente a su adhesión incondicional a la política norteamericana".

De esta manera, se abrieron las puertas del país para el ingreso directo y formal del colonia-

${ }^{4}$ Dicha declaratoria impactó en la vida de algunos investigadores tan influyentes como Max Uhle, quien en 1940 retorna al Perú pero es detenido junto con otros alemanes en el hotel Los Ángeles de Chosica (Bueno 2003: 20). 
lismo económico que, por aquellos años, se encontraba en una nueva fase de desartollo y era un reflejo de lo que acontecía en el continente americano. Asimismo, como bien señala Politis (1995: 207), esto también representaba "la disolución de los lazos entre Europa Occidental y Sudamérica". Durante el mandato de Prado y más aún, durante el gobierno de su sucesor José Luis Bustamante y Rivero (1945-1948), el APRA, que fue nuevamente legalizado por estos años, abandonó su primigenia lucha anticapitalista (Pease 1999: 194). Esto contribuyó a que existiese una estabilidad social y política, opuesta a la convulsionada situación política del decenio anterior ${ }^{5}$. Sin embargo, durante el posterior gobierno de Odría (1948-1956), y bajo la ley de seguridad interior, nuevamente se realizó una represión contra el APRA y el partido Comunista (Pease 1999: 213).

En el caso de la arqueología peruana, es justamente a partir de los años 40 cuando se inició una creciente y organizada llegada de investigadores e investigadoras estadounidenses, quienes formalizaron una arqueología histórico-cultural. Ésta, que llevaba varios años de desarrollo en los Estados Unidos y Europa, había comenzado a ser introducida por Julio C. Tello en sus estudios sobre los Andes, aunque sin un sustento teórico profundo. Un segundo grupo de arqueólogos norteamericanos comenzaría a introducir los presupuestos neoevolucionistas (principalmente desarrollados por Julian Steward para el caso americano) hacia los 50. Por tanto, en las décadas de los años 40 y 50, se desarrolló una arqueología fundamentada en la herencia del discurso de Tello ${ }^{6}$ y la arqueología histórico-cultural norteamericana, así como por la arqueología neoevolucionista emergente ${ }^{7}$. Esta nueva situación también fue propiciada por el vacío intelectual que dejó la muerte de Julio C. Tello en 1947 (Burger 1989: 38, Morales 1993: 22) y el consecuente abandono de las tesis difusionistas, principalmente sobre la "cultura matriz" de Chavín.

$\mathrm{La}$ influyente presencia de arqueólogos extranjeros determinó que gran parte de la arqueología nacional se viera plagada de discursos definidos por la teoría dominante. Por esos años, un investigador hará su deslinde con las ideas importadas por los arqueólogos norteamericanos, quienes coparon el espectro de la arqueología nacional mediante sus investigaciones y publicaciones. Nos referimos a la figura del peruano, hijo de inmigrantes chinos, Emilio Choy.

Choy fue un autodidacta que con sus escritos sentó las bases del análisis marxista formal en la prehistoria andina. Choy fue un marxista sin cobertura oficial que estuvo principalmente influenciado por Gordon Childe y su énfasis en la evolución y revolución como medio de cambio cultural. Al hablar de lucha de clases prehispánica e insertarla en el desarrollo social universal hacia el socialismo, Choy superó la anterior visión romántica del indigenismo. Para él, las sociedades peruanas emergieron de estructuras tribales igualitarias construyendo sociedades

5n diciembre de 1947 Prentice Cooper, embajador de Estados Unidos en el Perú, propuso a șu gobierno conferirle un grado honorario en alguna universidad norteamericana a Haya de la Torre (Haworth 1992: 184). De esta maneta, se consideraría al líder aprista alineado dentro de la política anticomunista estadounidense. De hecho, Aníbal Quijano planteó que el APRA habría retardado el crecimientó de una izquierda radical en el Perú (Liss 1984: 144).

"Aunque, las teorias difusionistas de Tello fueron negadas por los arqueólogos norteamericanos (v.g. Willey 1970 [1951]), muchos de ellos utilizaron los mismos presupuestos del arqueólogo peruano.

7 Estos investigadores prepararon el camino para la posterior llegada de otros arqueólogos norteamericanos fuertemente influenciados por la arqueología procesual. De hecho, entre los primeros y estos últimos no existe mucha separación teórica ya que comparten un sustrató teórico neoevolucionista. En el Perú, esta tendencia teórica se hace patente en 1977 cuando se hacen proyectos regionales como los de la Universidad de Michígan y UCLA, en los que participaron investigadores influyentes de la arqueología procesual como Timothy Earle, Kent Flannery o Joyce Marcus (Burger 1989: 43). 
jerárquicas con tendencia a la estructura de clases. Emilio Choy firma su primer artículo marxista relacionado a la prehistoria andina en 1955. Sin embargo, su principal aporte a la perspectiva teórica arqueológica marxista peruana será su escrito "La Revolución Neolítica y los orígenes de la civilización americana", presentado durante la semana de arqueología realizada en 1959 y cuyos textos fueron compilados en la publicación Antiguo Perú, espacio y tiempo (1960).

Si bien la producción intelectual de Choy fue esporádica e inorgánica, ésta se extendió entre 1945 y 1972. La UNMSM (Choy 1979) publicó una compilación de su obra, la que muestra un interés por diferentes épocas de la historia andina y, sobre todo, una línea teórica bastante consecuente a través de toda su vida intelectual.

Choy mantuvo un esquema bastante rígido de la evolución de las sociedades, utilizando los modos de producción esbozados por Marx en sus escritos juveniles. Asimismo, influenciado por Gordon Childe discute por primera vez en el Perú los argumentos desarrollados por el arqueólogo australiano (Macera 1974; Baquerizo 1979 : XV) y los utiliza como marco referencial articulador de los hallazgos arqueológicos en el área andina. Utilizando el libro Dawn of European Civilization (1925), donde Childe plantearía por primera vez la existencia de las "revoluciones" en la prehistoria europea, Choy reconoce las mismas revoluciones para elárea andina.

También reconoció (como Engels había ya planteado en el siglo XIX) el papel del trabajo como elemento principal en la evolución biológica e intelectual del ser humano en su artículo "El Trabajo en el Origen del Hombre Americano" (Choy 1974). Sin embargo, se puede reconocer la carga historicista cultural en su discurso, evidenciada en la utilización de las "culturas" paleolíticas europeas y su reflejo en América (Choy 1974: 102).

Aunque Choy llegó a dictar clases en la Universidad Nacional Mayor de San Marcos, su paso dejó una estela que muchos de sus seguidores han calificado más de informal que académica (por ejemplo, Macera 1974 o Baquerizo 1974). Lo que si queda claro es que gracias a él muchos estudiantes universitarios se nutrieron de una perspectiva marxista que les inspiró para proseguir su desarrollo académico.

\section{Tercer momento de la arqueología marxista: la} arqueología social peruana

La arqueología social latinoamericana (ASL), de la cual forma parte la arqueología social peruana, se ha descrito como una corriente teórica monolítica que pudo ser llevada a la práctica, básicamente, por la cobertura de gobiernos políticos ${ }^{8}$ (Tantaleán 2004). Las situaciones históricas en las que se instalaron en el poder dictaduras militares (por ejemplo en Perú), partidos de izquierda (por ejemplo México), revoluciones (como en Cuba en 1959) o una mezcla de dictaduras militares y partidos políticos de izquierda (como en Venezuela), posibilitaron el desarrollo de la arqueología marxista.

Por ejemplo, luego de la exitosa revolución cubana y con la política comunista instaurada en el poder, no se tardó en entrar al campo de la interpretación arqueológica dentro de una política dirigida desde el gobierno. En ese sentido, se debe el arqueólogo cubano $\mathrm{E}$. Tabío un importante trabajo materializado en el libro Prehistoria de Cuba de 1966 (Politis 1995: 219). En este libro introdujo el marco de análisis de la arqueología soviética ${ }^{9}$ y muchos estudiantes latinoamerica-

${ }^{5}$ Como muchos otros intentos de "etiquetamiento" de pensadores, se ha tratado de hacer a los arqueólogos de la arqueologia social latinoamericana coincidir dentro de un pensamiento unitario ("corriente teórica"). De esta manera, por ejemplo, Patterson (1994: 533) se presenta a los arqueólogos y arqueólogas sociales latinoamericanos como un frente teórico unitario utilizando una perspectiva y metodología enraizadas en el materialismo dialéctico. No estamos en total desacuerdo con Patterson respecto a esta definición epistemológica, pero creemos que esa sintetización de la ASL desmerece la historia (y la riqueza inherente a ella) de su formación en cada país. 
nos (por ejemplo en el Perú, donde Tabío condujo excavaciones arqueológicas) asimilaron sus planteamientos materialistas históricos (Aguirre-Morales 2001, Navarrete 1999: 24, OyuelaCaycedoet al. 1994:366).

En el Perú, durante la década del 60, asistimos a una época en que hay un avivamiento del movimiento ideológico de izquierda (Liss 1984: 139). Algunas facciones radicales del APRA crearon el MIR (Movimiento de Izquierda Revolucionaria) y elementos del Partido Comunista crearon el ELN (Ejercito de Liberación Nacional) (Pease 1999: 239-240). Asimismo, una ideología oficialista con tintes izquierdistas, o más bien populistas, se promovió durante el gobierno militar de Velasco Alvarado (1968-1975). Bajo este régimen, algunos investigadores hallaron una contexto necesario para impulsar una manera alternativa de hacer arqueología.

El caso de la política en el Perú de finales de la década de 1970 es singular debido a que la dictadura militar tomó la característica de "socialismo estatal" (Politis 1995: 215), con lo cual creó, por un lado, una coyuntura favorable para arqueólogos nacionales como Luis Lumbreras (Navarrete 1999), y por el otro lado, los arqueólogos norteamericanos encontraron dificultades para llevar a cabo sus investigaciones (Burger 1989: 42).

La llegada al poder de los militares en octubre de 1968 fue producto de una reacción a los gobiernos que aplicaron una política que por un lado, permitía y aseguraba a las empresas norteamericanas y a su aliada elite peruana el dominio del poder económico; mientras que, por el otro, permitía y justificaba la explotación de las masas campesinas y obreras. El general Juan Velasco Alvarado, presidente de la Junta Militar, sería quien lleve adelante un plan de gobierno revolucionario. Como él mismo afirmaría: "No somos marxistas, pero estamos haciendo una revolución, y esto es lo que importa" (Moreira 1975: 9).

Ese golpe militar, por vez primera, significó una independencia con respecto de los grupos de poder económico peruanos, por lo que había cierta libertad de acción en el desarrollo de los planes revolucionarios. Así, ya no existiría una "subordinación de la economía peruana a los centros de decisión donde se originan las acciones que afectan fundamentalmente a la vida económica de la nación e impide un proceso de desarrollo autónomo dirigido al logro de los objetivos nacionales" (Skidmore y Smith 1996:233).

Para ello, el gobierno se había sensibilizado notablemente con la causa campesina. Uno de sus objetivos fue proseguir con la Reforma Agraria, que se había iniciado tímidamente durante el gobierno de Belaúnde (Pease 1999: 232). Así, mediante una ley todos los grandes latifundios fueron expropiados y entregados a sociedades agrícolas de interés social. Pero mientras se realizaron aparentes mejoras en las condiciones de vida de la masa campesina y obrera, nunca se tuvo como objetivo conducir al Perú a una especie de socialismo. Por el contrario, el Estado buscó reducir la lucha de clases, la cual que ya había tomado un cariz violento, tutelando a los grupos de presión social y regulando las disputas civiles.

El régimen peruano en este momento podría catalogarse como un "Estado corporativo típico" (Skidmore y Smith 1996: 235). En esa misma línea política, otro objetivo que se logró fue el de la "nacionalización" o expropiación de los sectores productivos estratégicos, como el de la minería y el petróleo (Skidmore y Smith 1996: 236). Si bien esto despertó la hostilidad de los Estados Unidos, pronto se llegó a un acuerdo por el cual el gobierno peruano compensó económicamente a las empresas norteamericanas.

9 Aquí también habría que mencionar el posterior trabajo de Antonio Núnez Jiménez en el registro de los petroglifos del Perú (Núñez Jiménez 1986). Si bien este trabajo casi siempre fue consultado como un inventario de arte rupestre, supuso la colaboración e intercambio de conocimientos entre arqueólogos peruanos y cubanos. 
Sin embargo, la ilusión populista pronto entró en crisis y el descontento social no se hizo esperar. Una nueva crisis económica en 1975 (Deniz 1978: 10), más los problemas de salud de Velasco, provocaron que el experimento militar fracasará. En 1975, Velasco fue reemplazado por una Junta Militar liderada por el General Francisco Morales Bermúdez, quien desmantelaría la obra de su antecesor. Las presiones del Fondo Monetario Internacional (FMI) hicieton que el gobierno se ajustará al anterior programa económico establecido, lo que provocó nuevos problemas en la economía peruana. Morales Bermúdez se vio obligado a abrir nuevamente las puertas a las inversiones extranjeras, otorgándoles grandes concesiones (Deniz 1978: 12). Finalmente, la propia Junta Militar anunció la convocatoria a una Asamblea Constituyente en 1978, con lo que se inició la transición hacia la democracia.

Con respecto a la arqueología marxista, tuvo que llegar el año 1974 y la publicación de obras como la Arqueología como Ciencia Social de Luis Lumbreras (Politis 1995:219) para que un nuevo discurso alternativo al de los arqueólogos extranjeros y sus seguidores sea formalizado. Como consecuencia, se promovieron una serie de reuniones donde se impulsó la construcción de la llamada arqueología social latinoamericana (ASL). La primera de ellas, la Reunión de Teotihuacán de 1975 (Lorenzo 1976), pretendió establecer unas líneas generales de acción en la perspectiva materialista histórica que cada uno de los participantes desarrollaba en sus respectivos países. Vinó luego una segunda reunión en el XL Congreso Internacional de Americanistas, celebrado en Lima en 1970, y que fue denominado "Formaciones aborígenes en América" (Patterson 1994: 533). Luego de estos primeros intentos se creó el denominado "Grupo de Oaxtepec" en
1983, conformado por Luis Lumbreras, Manuel Gándara, Mario Sanoja, Marcio Veloz, Iraida Vargas y Luis Felipe Bate (Politis 1995: 220). Esta nueva época es denominada por Navarrete (1999: 89) como de "refinamiento teórico".

Este grupo adoptó una posición crítica frente al materialismo estructuralista francés (de Althusser y Godelier), tan popular en esos años, principalmente porque dicha "escuela" planteaba una división de la sociedad objeto de estudio ("totalidad social") entre base económica y superestructura. Paradójicamente, mucha de la teoría y metodología histórico-cultural, evolucionista y marxista estructuralista se deslizó en los discursos de los arqueólogos sociales (v.gr. Lumbreras 1974:24).

\section{Una nueva visión del antiguo Perú: Luis G. Lumbreras $^{10}$}

Luis Guillermo Lumbreras se desarrolló académica y políticamente en la época en que ejerció como profesor en la Universidad San Cristóbal de Huamanga, en Ayacucho, entre 1960 y 1965 . La mayor parte de su trabajo académico y de campo transcurrirá paralelo al gobierno militar de Velasco Alvarado (1968-1975), coyuntura favorable para desarrollar sus investigaciones arqueológicas más relevantes (OyuelaCaycedo et al. 1994: 367) y asumir "el rol de Tello al definir tendencias y prioridades en la prehistoria andina" (Schaedel y Shimada 1982: 363).

Para no entrar en más detalles que ya bien han explicado otros autores (Aguirre-Morales 2001, Navarrete 1999: 11-20) yél mismo (Lumbreras 2005), la época de la producción bibliográfica de Lumbreras que más nos interesa es cuando abandona su formación evolucionista y positivista y se decanta por el marxismo, alrededor de 1972, y que lo plasma en su libro Los orígenes de la civilizaciónen el Perú.

10. La producción intelectual de otros miembros del INDEA como Elías Mujica Barreda fue abordada en otro artículo (Tantaleán 2002). Aunque fue uno de los pocos arqueólogos que ha planteado una explicación materialista histórica de las sociedades tempranas del área Circum-Títicaca, desde su primer escrito de 1978, salta a la vista la "he- 
En otro artículo (Tantaleán 2004), ya hemos realizado un análisis algo extenso de su más celebre libro La Arqueología como Ciencia Social, e, incluso el mismo Lumbreras (2005) ha reflexionado sobre sus primeros escritos, por lo que no nos explayaremos en esto. Lo que si queda claro, a la luz del libro anteriormente citado, es que Lumbreras tenía bastante interiorizada la teoría y el método del materialismo histórico. También tenía bastante clara la perspectiva dialéctica de la realidad social y su representación. Sin embargo, la manera de llevarla a la práctica es un elemento inexistente en dicho documento, quizá como consecuencia de su carácter de manifiesto primigenio de esta nueva forma de observar la materialidad social o, como algún autor ha sugerido (Navarrete 1999), aspiraría a convertirse en un discurso popular para construir un programa político revolucionario.

Como también mencionamos con anterioridad, la Gaceta Arqueológica Andina debería (re)presentar la línea de pensamiento de Lumbreras y de su colectivo: el Instituto Andino de Investigaciones Arqueológicas (INDEA) ${ }^{11}$.

Sin embargo, un análisis realizado (Tantaleán 2004) de esta revista especializada durante los años que contó con mayor regularidad (1982. 1990) reveló que de los 137 textos (artículos o editoriales) revisados, solamente 32 podían relacionarse efectivamente con el materialismo his-

Luis Guillermo

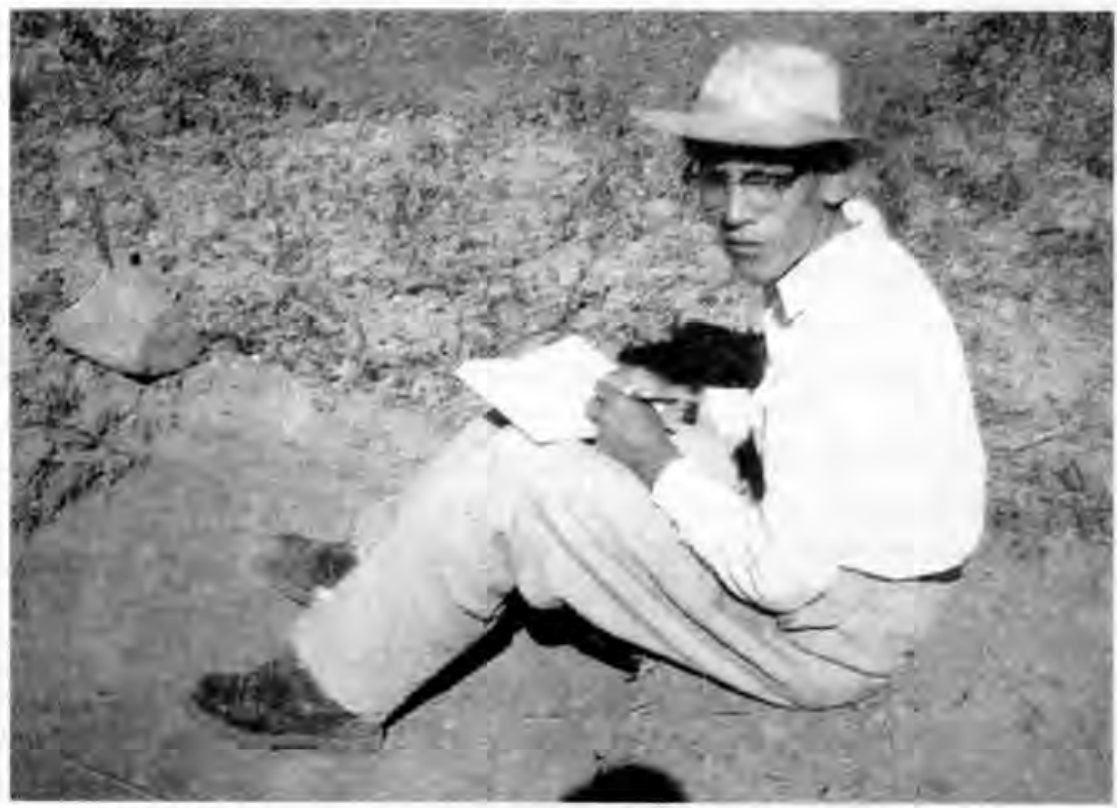

rencia culturalista" de la cual el mismo autor es consciente (Mujica 1978: 296). Caerá en la misma forma de hacer arqueología histórico-cultural y hermenéutica en su posteriores artículos, y se observa el uso de categorías sociopolíticas extraídas del procesualismo (1991). Otro autor no analizado aquí con la profundidad del caso es José Canziani, aunque lo desligamos de este análisis porque su producción ha sido esporádica, salvo su Asentamientos humanos y formaciones sociales en la costa norte del Antiguo Perú (Canziani 1989) que nos parece un esbozo bastante sugerente de la arqueología de la costa norte pero que, lamentablemente, no siguió desarrollando y no fue seguido por ningún otro arqueólogo.

" Obviamente, la crisis política, social y económica por la que ha atravesado el Perú en estos últimos años y que ha condicionado la arqueología hasta el punto de hacerla por algunos momentos impracticable (Castillo y Mujica 1995, Pozzi-Escot 2002: 146), ha afectado la historia de esta revista. Lamentablemente, no desarrollaremos estas cuestiones por el poco espacio disponible. 
TEXTOS SEGUN ESCUELA TEORICA EN LA GACETA ARQUEOLOGICA ANDINA 1982 - 1990

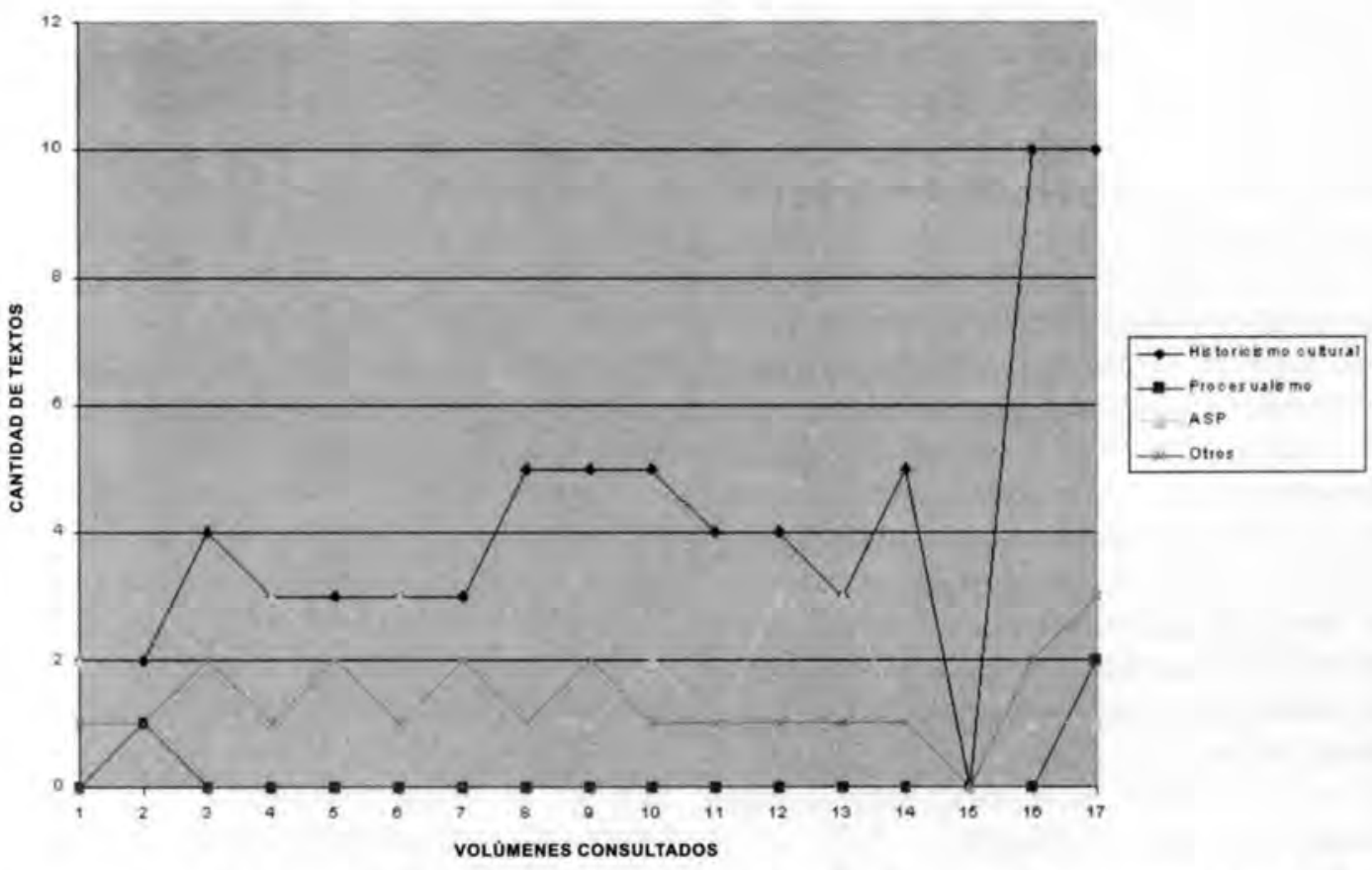

tórico y que son básicamente las pocas editoriales y artículos de teoría y metodología escritos por Lumbreras (casi todos reproducidos en Lumbreras 2005). Por el contrario, la mayoría de los textos (unos 75) están relacionados con el historicismo cultural, a pesar que estos suponían una perspectiva "colonialista y burguesa", tal como se anunciaba en las editoriales de los mismos números. Asimismo, la presencia de artículos de inspiración procesualista es escasa.

De esta forma, la Gaceta Arqueológica Andina se convirtió en una publicación que amalgamó a las diferentes tendencias teóricas de los arqueólogos que trabajaba sobre los Andes Centrales y que serían en primer lugar historicistas-culturales y, en segundo, procesualistas (Politis 2003: 248). La Gaceta Arqueológica Andina, además de reflejar la ausencia de una robusta escuela de arqueólogos formados teóricamente dentro del materialismo histórico, también refleja la situación de la arqueología peruana donde la mayoría de arqueólogos siguen siendo tanto teórica como metodológicamente historicistas culturales, casi siempre descriptivos y en el mejor de los casos utilizando jerga procesualista o marxista para "modernizar" su discurso.

\section{¿Existe un futuro para la arqueología marxista peruana?}

Como hemos visto, la arqueología marxista en el Perú ha recorrido una larga experiencia en el trabajo arqueológico. De hecho, es una "escuela" o "corriente" teórica que a nivel historiográfico se reconoce tanto en el país como en el extranjero (Benavides 2001, Mc Guire 1992, Navarrete 1999, Oyuela-Caycedo et al. 1997, Patterson 1994, 1997). Sin embargo, en este artículo se ha podido observar que la arqueología marxista en el Perú ha estado condicionada por diferentes factores, sobre todo las situaciones económicas y políticas. En algunos casos las coyunturas políticas han servido para que este 
discurso sea prominente en las esferas académicas y oficiales. Por el contrario, al aparecer discursos políticos oficiales diferentes $\mathrm{u}$ opuestos al marxismo ha caído en la marginación y hasta la persecución, hecho que se percibe en las últimas décadas, y que la ha sumido en una aparente apatía, patente en su mínima y decreciente producción bibliográfica.

Creemos que para superar este panorama, la arqueología marxista en el Perú necesita redefinirse como una verdadera ciencia y llegar a realizarse mediante una praxis que sea coherente con sus ideales y retórica. Estos últimos, por el momento, son más significativos que su materialización en casos concretos de estudio (Politis 2003: 251). Pero, sobre todo, se necesita desplegar una teoría de la observación arqueológica a partir de las líneas fundamentales del materialismo histórico: una verdadera epistemología materialista histórica refrendada con el objeto de estudio, en nuestro caso, los restos de la producción material de la vida social pasada.

En ese camino, miembros de la "segunda generación" del INDEA formaron un colectivo denominado "Gabinete de Arqueología Social", publicando sus primeros manifiestos a finales del siglo pasado (GARSOC 1998(1), 1998(2), 1998(3), 1999(4)), y han comenzado a desarrollar un discurso materialista histórico bastante consecuente con dicha posición teórica (v.gr., Alcalde 2001, Alcalde et al. 2001, 2002) que ha trascendido las fronteras nacionales como consecuencia de la inserción de algunos de sus miem- bros en programas de estudios marxistas del Estado Español.

Otros intentos inspirados en el marxismo proceden de grupos de estudiantes universitarios que desde sus fueros y autónomamente han manifestado posiciones más críticas que desarrollos concretos, como en los casos del colectivo RVNA de la Universidad Nacional Mayor de San Marcos o el colectivo SUPAY de la Universidad Nacional Federico Villarreal, grupos que esperamos se consoliden e integren a la escena marxista internacional y, sobre todo, lleven a la práctica arqueológica sus ideales. ${ }^{12}$

Estos intentos de desarrollar una arqueología marxista en el Perú de fines de siglo XX y comienzos del XXI, nos muestran una suerte de "balcanización" en dicha postura, no analizada profundamente aquí, pues tampoco se explicita su ontología ni su epistemología y más bien resultan ser simplemente retóricas. Aunque en ninguno de los casos mencionados se percibe un intento de unificación o discusión seria de sus enunciados o posición teórica, creemos que si se supera dicha situación se podrá construir una corriente teórica con capacidad de superar las deficiencias infraestructurales que han lastrado el desarrollo del trabajo empírico y contrastante de muchos de sus postulados, todo ello basado y conducente a la colectivización de los conocimientos científicos ${ }^{13}$. De no ser así, pronto nos encontraremos a la espera de un nuevo arqueólogo oficial que sea la esperanza para llegar al poder (intelectual).

${ }^{12}$ En el caso de la revista Unay Rvna del colectivo Rvna, la tendencia es comenzar la publicación con una editorial con tintes anti-capitalistas (Rvna 1999, 2001, 2003) y un contenido que puede incluir algún artículo de crítica arqueológica inspirado en el materialismo histórico (por ejemplo, Aguilar 2005, Gándara 2003, Torres 1999), aunque la mayoría de los textos no tienen ninguna relación con el marxismo o una postura crítica a la arqueología inspirada en el neoliberalismo económico. Un fenómeno similar ocurre con la Revista Supay (ver por ejemplo, Supay 1999, 2003). Aparte de esto, algo relevante es que ambos colectivos han creado revistas donde se reúnen a otros especialistas de las ciencias sociales, superando la fragmentación o "parcelamiento" propio de la academia clásica.

${ }^{13}$ No es necesario buscar tan lejos pues, por ejemplo, algunos investigadores chilenos han retomado el marxismo para aplicarloa la materialidad social prehispánica (ver Chungará 36, suplemento especial, tomo 1). 
Bibliografía

Águilar, Miguel

2005 "Posmodernismo y pensamiento Filosófico. El Sentido del Trabajo Arqueológico en América Latina". Unay Rvna, 7:25-31. Lima.

Aguirre-Morales, Manuel

2001 "La Arqueología Social en el Perú", Tesis de Maestría. Doctorado de Arqueología Prehistórica. Universidad Autónoma de Barcelona. España.

Alcalde, Javier

2001 "Del registro arqueológico a la reconstrucción del espacio productivo. Un caso de la costa sur del Perú" (S. X a. CV d.C). Arqueologia Espacial, 23: 15-38. Teruel.

Alcalde, Javier, Carlos del Águila y Fernando Fujita

2001 "Nuevas evidencias en Chincha: Nota preliminar sobre contextos de la época Wari". Boletin de Arqueología PUCP, 5: 543-554. Lima.

Alcalde, Javier, Carlos del Águila, Fernando Fujita. y Enrique Retamozo

2002 "Plateros precoloniales tardíos en Tambo de Mora, valle de Chincha (Siglos XIV-XVI)". Anales del Museo de América, 10. Madrid.

Baquerizo, Manuel

1979 "Emilio Choy y su influencia en el Perú. En Choy, Emilio. Antropología e Historia,

Baudin, Louis 1:XI-XXV.UNMSM, Lima.

[1928]1955 El Imperio Socialista de los Incas.

Benavides, Hugo Santiago de Chile: Zig-Zag.

2001 "Returning to the Source: Social Archaeology as Latin American Philosophy". Latin American Antiquity, $12(4): 355-370$.

Bueno, Alberto

2003 "Pachacamac. El sitio del poder de la Tierra y Max Uhle" (25-03-1856/11-05. 1944). En Uhle, Max. Pachacamac. Informe de la Expedición peruana William Pepper de 1896. Fondo editorial de la
Universidad Nacional Mayor de San Marcos. Lima.

Burger, Richard

1989 "An Overview of Peruvian Archaeology" (1976-1986). Annual Review of Anthropology, 18: 37-69.

Canziani, José

1989 Asentamientos Humanos y Formaciones Sociales en la Costa Norte del Antiguo Perú. INDEA. Lima.

Castillo, Luis Jaime y Elías Mujica

1995 "Peruvian Archaeology: Crisis or Development?". SAA Bulletin, 13(3).

Childe, Gordon

1925 The Dawn of European Civilization. Kegan Paul, Trench, Trubner \& Co., LTD. London.

Choy, Emilio

1960 "La Revolución Neolítica en los Orígenes de la Civilización Americana". En Antiguo Perú, Espacio y Tiempo: 149. 197. Mejía Baca. Lima.

1974 Antropología e Historia, 1. UNMSM. Lima

Cotler, Julio

1978 Clases, Estado y Nación en el Perú. Instituto de Estudios Peruanos. Lima.

2005 Clases, Estado y Nación en el Perú. 3era edición. Instituto de Estudios Peruanos. Lima.

Deniz, José

1978 La Revolución por la Fuerza Armada. Sígueme. Salamanca.

Gándara, Manuel

2003 "La adopción de teorías en antropología y arqueología Latinoamericana". Unay Rena, 6: 15-18. Lima.

GARSOC

1998(1), 1998(2), 1998(3), 1999(4).

Gabinete de Arqueología Social (GARSOC). Lima.

Haworth, Nigel

1992 "Perú". En Bethell, Leslie e Ian Roxborough (eds.): Latin American Between the Second World War, 1944. 1948. Cambridge University Press. New York. 
Liss, Sheldon

1984 Marxist Thought in Latin America. University of California Press. Berkeley y Los Ángeles.

Lorenzo, José Luis (cord.)

1976 "Hacía una arqueología social". Reunión en Teotihuacan (octubre de 1975). INAH. México.

Lumbreras, Luis G.

1974 La arqueología como ciencia social. Histar. Lima.

1991 "Historia de la arqueología peruana". En Los Incas y el Antiguo Perú. 3000 Años de historia: 486-498. Centro Cultural de la Villa. Madrid.

2005 "Introducción". En Gonzáles Carré, Enrique y Carlos del Águila (eds.): Arqueología y Sociedad: 21-43. IEP. Lima.

Macera, Pablo

1979 "Emilio Choy: Un Hombre de Futuro". En Choy, Emilio: Antropología e Historia, 1: XXVI-XXXIII. UNMSM, Lima.

McGuire, Randall

1992 A Marxist Archaeology. Academic Press. San Diego.

Mariátegui, José Carlos

[1928]1994 7 Ensayos de Interpretación de la Realidad Peruana. 60va edición. Amauta. Lima.

Montoya, Rodrigo

1999 Todas las sangres: Ideal para el futuro del Perú. Disponible en www.andes.missourri.edu/andes/arguedas/rmcritica/rm_critica2. html.

Morales, Daniel

1993 "Introducción". En Historia Arqueológica del Perú (Del Paleolítico al Imperio Inca). Compendio histórico del Perú. Milla Batres. Lima.

Moreira, Neiva

1975 La vía revolucionaria peruana. Avance. Barcelona.

Mujica, Elías

1978 "Nuevas hipótesis sobre el desarrollo temprano del altiplano, del Titicaca y de sus áreas de interacción. Arte y Arqueología, 5 y $6: 285$ - 308. La Paz.

1987 "Cusipata: Una fase Pre-Pukara en la cuenca norte del Titicaca". Gaceta Arqueológica Andina, 13: 22-28. INDEA. Lima.

1991 "Pukara: Una socied..d compleja temprana en la cuenca norte del Titicaca". En Los incas y el Antiguo Perú. 3000 años de historia. Madrid.

Navarrete, Rodrigo

1999 "Latin american social archaeology: One goal, multiple views". Tesis de Maestría de Artes en Antropología. Binghampton University. State University of New York.

Núñez Jiménez, Antonio

1986 Petroglifos del Perú. Panorama Mundial del Arte Rupestre. Editorial CientíficoTécnica. La Habana.

Oyuela-Caycedo, Augusto, Armando Anaya, Carlos Elera y Lidio Valdez

1997 "Social Archaeology in Latin America?: Comments to T.C. Patterson". American Antiquity, 62(2): 365-374.

Patterson, Thomas

1986 "The last sixty years: Towards a social history of americanist archaeology in the United States". American Anthropologist, 88: 7-23.

1994 "Social archaeology in latin america: An appreciation". American Antiquity, $59(3) \div 531-537$.

1997 "A reply to Oyuela-Caycedo, A. Anaya, C. G. Elera, and L. M. Valdez". American Antiquity, 62(2): 375-376.

Pease, Franklin

1999 Breve historia contemporánea del Perú. Fondo de Cultura Económica. México.

Politis, Gustavo

1995 "The socio-politics of the development of archaeology in hispanic South America". En Ucko, Peter (ed.). Theory in Archaeology. A World Perspective: 197. 235. Routledge. Londres. 
2003 "The theoretical landscape and the methodological development of archaeology in Latin america". American Antiquity, 68(2): 245-272.

Pozzi-Escot, Denisse

2002 "Arqueologia peruana: Una Síntesi". Cota Zero, 17: 141-150. Vic.

Quijano, Anibal

1985 Imperialismo, clases sociales y Estado en el Perú, 1890-1930. Mosca Azul. Lima.

RVNA

Unay Rvna. Revista de Ciencias Sociales, 1999(3), 2001 (5), 2003 (6), 2005 (7). Lima.

Schaedel, Richard e Izumi Shimada

1982 "Peruvian archaeology, 1940-1980: An analytic overview". World Archaeology, 13:359-371.

Skidmore, Thomas y Peter Smith

1996 Historia contemporánea de América Latina. América Latina en el Siglo XX. Crítica. Barcelona.

SUPAY

2003 Supay. Revista de humanidades y ciencias del hombre, 4. Lima.

Tantaleán, Henry

2002 "El Felino en la Roca: La formación del Estado Prehispánico en la cuenca Norte del Titikaka, Perú". Tesis de Maestría. Doctorado en Arqueología
Prehistórica. Universidad Autónoma de Barcelona. España.

2004 "L'Arqueologia Social Peruana: Mite o Realitat?". Cota Zero, 19: 90-100. Vic.

Torres, Daniel

1999 "Breves consideraciones en torno a la arqueología social latinoamericana de cara al próximo milenio". Unay Runa, 3: 4-9. Lima

Valcárcel, Luis E.

1925 "Informe sobre las Exploraciones Arqueológicas en Pukará". Revista Universitaria del Cuzco, 48; 14-21. Cuzco.

1927 Tempestad en los Andes. La Sierra, 1(10). Lima.

1932a "El gato de agua. Sus representaciones en Pukara y Naska". Revista del Museo Nacional, 4 (1): 3-27. Lima.

1932 b "El Personaje Mítico de Pukara". Revista del Museo Nacional, I (1): 18-31. Lima.

1935 "Litoesculturas y cerámica de Pukara". Revista del Museo Nacional, 4(1): 25-28. Lima.

Willey, Gordon

1952 "A survey of South American archaeology". Journal of the Royal Anthropological Institute of Great Britain and Ireland, 83(1): 56-64. 